\title{
Comportamento exploratório de potros e éguas mediante a introdução de novos objetos em seu meio
}

Erica Cristina Bueno do Prado GUIRRO ${ }^{1,2}$

Patrícia Cruz BARBALHO ${ }^{3}$

Mateus José Paranhos da $\operatorname{COSTA}^{1}$

\section{Correspondência para:}

Hospital Veterinário- UniversidadeFederal do Paraná/UFPR - Campus Palotina Rua Pioneiro, 2153 - Jd. Dallas CEP 85950-000 Palotina / PR, (44) 3649-

1214, ericaguirro@ufpr.br

Recebido para publicação: 18/01/2007 Aprovado para publicação: 27/11/2008

\author{
1 - Faculdade de Ciências Agrárias e Veterinárias da Universidade Estadual \\ Paulista, Jaboticabal - SP \\ 2 - Universidade Federal do Paraná, Palotina - PR \\ 3 - Zootecnista Autônoma
}

\section{Resumo}

Comportamento exploratório é a atividade que o animal realiza para aumentar sua interação com o meio após ser motivado pela curiosidade e só é exibido quando o animal se sente num ambiente livre de tensão. O objetivo deste estudo foi medir o comportamento exploratório de potros e éguas mediante a introdução de objetos desconhecidos. Para tanto, quatro potros e éguas foram observados durante sete sessões diárias de 60 minutos, sempre com o uso de um objeto diferente. Não se observou diferença nas freqüências de olhar, dirigir-se ou tocar no objeto entre potros e éguas. O tempo total de toque foi de 45,6 minutos, divididos em 64 toques, concentrados principalmente nos 20 minutos iniciais de cada sessão. Embora não tenha sido verificada diferença no número de aproximações solitárias ou aos pares e, na aproximação aos pares, não tenha havido diferença no número de iniciativas de aproximação por parte de potros ou éguas, observou-se que os potros aproximaram-se de forma solitária mais vezes que suas mães. Verificou-se que não foi sempre o mesmo animal quem tocou no objeto primeiro, mas notou-se que quatro animais revezaram-se nesta posição. Dessa forma, concluiu-se que a introdução de objetos desconhecidos no ambiente serve de motivação para que éguas e potros exibam comportamento exploratório semelhantes, todavia os potros apresentam maior atividade de manipulação e têm mais iniciativa de aproximação solitária, sugerindo que os potros são mais curiosos que as éguas. A predisposição de alguns animais por tocar no objeto primeiro, possivelmente, indique diferenças individuais no grau de curiosidade.

\section{Introdução}

Comportamento exploratório é o tipo de atividade que o animal realiza para aumentar sua interação com o meio, após ser motivado pela curiosidade, semelhante ao que ocorre em humanos. ${ }^{1,2}$ Nesta investigação, o animal dirige para o objeto de sua curiosidade praticamente todos os padrões comportamentais que estiverem à sua disposição, entretanto este comportamento só é verificado quando o animal se sente num ambiente livre de tensão. O significado biológico deste comportamento é conhecer

\author{
Palavras-chave: \\ Comportamento exploratório. \\ Curiosidade. \\ Eqüinos. \\ Potros.
}

melhor o meio, a fim de otimizar suas chances de sobrevivência frente às adversidades futuras, na forma de conhecimento latente. ${ }^{2}$

Já se verificou que a esterilidade do meio atua de modo diretamente proporcional no comportamento exploratório de bezerros ${ }^{3}$ e leitões ${ }^{4}$. Ademais, a privação de novidades leva à hiper-reatividade quando uma nova situação deve ser enfrentada. ${ }^{5}$

A maioria dos estudos sobre avaliação do comportamento exploratório utilizou ratos ${ }^{6,7,8,9,10}$, mas existem algumas informações a respeito deste comportamento em frangos ${ }^{11}$, bezerros $^{3,12,13}$, leitões ${ }^{4,14,15}$ e cães ${ }^{16}$, sendo que 
neste último o modelo experimental incluiu a introdução de objetos desconhecidos no ambiente. Embora eqüinos sejam extremamente reativos, tenham alerta de origem multi-sensorial e vigilância instantânea especialmente no primeiro ano de vida ${ }^{17}$, inexistem informações a respeito do comportamento exploratório desta espécie, principalmente em potros, que uma hora após o nascimento já utilizam visão mono e binocular, movimentam as orelhas em busca de ruídos, adotam o sentido olfativo, tátil e, possivelmente, gustativo a fim de investigar o meio em que vivem. ${ }^{18}$

Conforme a disponibilidade de recursos, os eqüinos estabelecem grupos grandes, constituídos por diversos subgrupos denominados de bandos, nos quais os potros permanecem por cerca de três anos $^{17}$. É possível que tal organização social gregária influencie no comportamento exploratório dos animais jovens.

Avaliando-se o comportamento exploratório de ratos, verifica-se que após a estimulação dos órgãos sensoriais externos há aumento da excitação do sistema nervoso central, especialmente na formação reticular e na amígdala, quando o estímulo é considerado relevante. ${ }^{19,20,21,22,23,24,25} \mathrm{O}$ controle dessa integração ainda é desconhecido, porém sugere-se que o comportamento exploratório não tenha origem motivacional como a sede, fome ou comportamento sexual, mas dependa de sistemas mais específicos. ${ }^{26}$

Assim, o estudo do comportamento exploratório gerado pela curiosidade de potros e éguas pode auxiliar no entendimento da biologia da espécie eqüina, além de tentar explicar parte do desenvolvimento da autoconfiança verificada nos animais adultos, característica extremamente desejável em equiinos de trabalho ou atletas. Nesse sentido, o objetivo geral do presente estudo foi verificar como potros se comportam diante da introdução de objetos desconhecidos que sirvam de desafio a eles. Os objetivos específicos foram verificar se a introdução de objetos desconhecidos no piquete dos potros é capaz de despertar curiosidade suficiente para motivá-los a exibir comportamento exploratório, se é sempre o mesmo animal quem chega primeiro no objeto e se a égua acompanha o potro na aproximação ao objeto.

\section{Material e Método}

Este estudo foi submetido e aprovado pelo Comitê de Ética e Bem-estar Animal da Faculdade de Ciências Agrárias e Veterinárias - FCAV / UNESP (protocolo $\mathrm{n}^{\circ}$ 009091-07).

Foram selecionados quatro potros lactentes de 25 a 75 dias de vida, um macho e três fêmeas, acompanhados pelas éguas. As éguas foram numeradas como 1, 3, 5 e 7 e os potros 2, 4, 6 e 8, respectivamente. Todos os animais eram da raça Brasileiro de Hipismo $(\mathrm{BH})$ e viviam num pasto de cerca de $5500 \mathrm{~m}^{2}$, coberto por capim tifton (Cynodon dactilum). Em busca de ambiente mais estéril, o experimento foi conduzido num piquete de $956 \mathrm{~m}^{2}$, desprovido de forragem e cercado por madeira e arame liso.

Os oito animais eram trazidos ao piquete menor para que se habituassem e, só após 30 minutos, os objetos eram introduzidos. A cada dia, um novo objeto era utilizado, sempre colocado no solo ou preso numa altura máxima de 1 metro, para permitir o contato com os potros.

Foram realizadas sete sessões de 60 minutos de observação. No intuito de evitar variações, tais observações foram feitas à distância e iniciaram-se às 18:30h, quando não havia mais funcionários presentes no setor e a temperatura era amena, já que o estudo foi realizado no mês de janeiro. As categorias observadas incluíram:

- olhar para o objeto: ato de dirigir a cabeça, apontar as duas orelhas e focar atentamente o objeto;

- dirigir-se ao objeto: andar em direção ao objeto, sendo que esta categoria foi subdividida em classes:

- diretamente: o animal sai de onde está e vai para o objeto sem parar nenhuma vez antes de alcançá-lo; 
- parar uma vez: o animal dirige-se ao objeto, mas pára uma vez antes de alcançá-lo;

- parar mais de uma vez: o animal dirige-se ao objeto, mas pára mais de uma vez antes de alcançá-lo;

- tocar o objeto: ato de encostar intencionalmente qualquer parte do corpo no objeto;

Os objetos empregados foram, na ordem de utilização, uma caixa coberta por plástico azul colocado no solo, oito garrafas plásticas suspensas numa cerca a $1 \mathrm{~m}$ de altura, um travesseiro preso à cerca junto ao solo, uma bola presa à cerca junto ao solo, dois chocalhos a $1 \mathrm{~m}$ de altura, um bambolê coberto por papel prateado colocado a $1 \mathrm{~m}$ de altura e plumas coloridas presas em três bolas com guizos internos a $1 \mathrm{~m}$ de altura. Cabe salientar que os objetos que foram suspensos a $1 \mathrm{~m}$ eram presos por barbante de algodão.

Os dados foram coletados de forma contínua, direta e não-invasiva antes de serem submetidos à análise conforme as características das variáveis. ${ }^{27}$ Assim, utilizouse o teste-t $(\mathrm{p}>0,05)$ para comparar a freqüência das categorias observadas entre cada égua e seu potro, o tempo de toque entre cada égua e seu potro e o tempo de toque entre éguas e potros. Empregou-se o teste ANOVA de uma via seguido pelo teste Student-Newman-Keuls $(\mathrm{p}>0,05)$ para comparação pareada múltipla do tempo de toque entre todos os animais

\section{Resultados}

Durante as sete sessões de observações, aconteceram 64 aproximações aos objetos, considerando o fato dos animais tocarem no mesmo objeto mais de uma vez no dia. Ocorreram aproximações solitárias e aos pares, sendo que par foi definido como o conjunto formado pela égua e seu respectivo potro e considerou-se aproximação pareada quando ambos os membros do par aproximaram-se e tocaram no objeto num intervalo máximo de 1 minuto. Nesse contexto, não se notou diferença estatística entre as aproximações aos pares $(40,9 \%)$ ou solitárias $(59,1 \%)$. Na aproximação aos pares, $55,6 \%$ das vezes a iniciativa foi dos potros e em $44,4 \%$ a iniciativa foi das éguas, também sem diferença estatística. Quanto à aproximação solitária, houve mais aproximação de potros $(82,1 \%$ ) que de éguas $(17,9 \%)$, todavia na maioria das vezes tal aproximação ocorreu após aproximação prévia das éguas. Esses dados podem ser visualizados na tabela 1 .

A tabela 1 exibe a ordem de chegada dos animais aos objetos. Embora não tenha sido sempre o mesmo indivíduo quem se aproximou primeiro, observou-se que quatro animais mantiveram esse posicionamento: potro $2(28,6 \%)$, égua 5 $(28,6 \%)$, égua $7(28,6 \%)$ e potro $8(14,3 \%)$.

A figura 1 ilustra a somatória de cada uma das categorias observadas, para cada animal. A categoria "dirigir-se ao objeto, parar mais de uma vez" não foi ilustrada graficamente pois não foi exibida pelos animais.

Os animais tocaram nos objetos por 45,6 minutos durante as sete sessões de observação. Verificou-se maior intensidade de exploração dos objetos pelos potros, principalmente nos 20 minutos iniciais de observação, conforme pode ser visualizado na tabela 2 e na figura 2 . A tabela 2 exibe o tempo de toque individual e das categorias égua e potro, em minutos e em percentagem, enquanto que a figura 2 ilustra o tempo de toque de cada animal a cada intervalo de 10 minutos.

\section{Discussão}

Considerando que o comportamento exploratório é motivado pela curiosidade quando o animal sente-se seguro num ambiente $^{2}$, pode-se inferir que o protocolo utilizado neste estudo foi eficiente, pois o tempo de 30 minutos pareceu ser suficiente para habituá-los ao piquete e a introdução dos objetos desconhecidos motivou a exploração. É muito provável que o estado de alerta de origem multi-sensorial, vigilância instantânea e marcante reatividade dos 
Tabela 1 - Seqüência dos animais que tocaram os objetos durante as sessões de observação, considerando todos os toques de cada animal. As áreas marcadas em cinza exibem as aproximações aos pares Jaboticabal - 2006

\begin{tabular}{|c|c|c|c|c|c|c|c|}
\hline & \multicolumn{7}{|c|}{ Sessão de Observação } \\
\hline & $1^{\mathrm{a}}$ & $2^{a}$ & $3^{a}$ & $4^{a}$ & $5^{a}$ & $6^{\mathrm{a}}$ & $7^{\mathrm{a}}$ \\
\hline \multirow{20}{*}{ 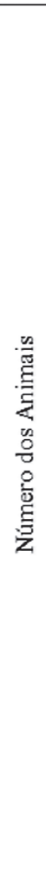 } & 2 & 7 & 5 & 8 & 5 & 7 & 2 \\
\hline & 1 & 8 & 6 & 8 & 6 & 2 & 7 \\
\hline & 6 & 1 & 4 & 2 & 6 & 6 & 4 \\
\hline & 5 & 2 & 1 & 7 & 6 & & 6 \\
\hline & 2 & 8 & 2 & 8 & 6 & & 8 \\
\hline & 1 & & & 4 & 6 & & 6 \\
\hline & 2 & & & 4 & 5 & & 5 \\
\hline & 6 & & & 8 & 6 & & 3 \\
\hline & 6 & & & 4 & & & 2 \\
\hline & 2 & & & 3 & & & \\
\hline & 4 & & & 5 & & & \\
\hline & 3 & & & 6 & & & \\
\hline & 4 & & & 8 & & & \\
\hline & 6 & & & 2 & & & \\
\hline & & & & 6 & & & \\
\hline & & & & 8 & & & \\
\hline & & & & 4 & & & \\
\hline & & & & 6 & & & \\
\hline & & & & 2 & & & \\
\hline & & & & 4 & & & \\
\hline
\end{tabular}

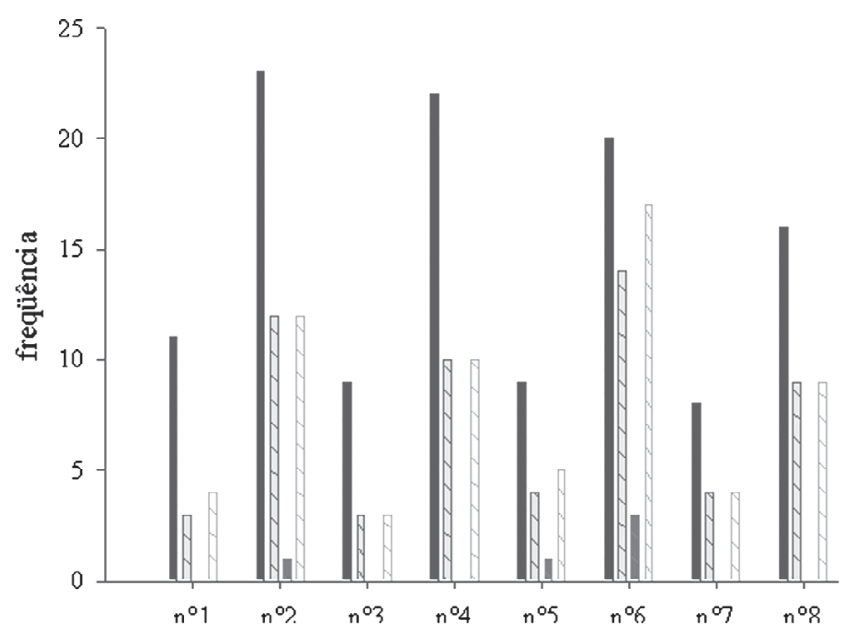

olhar para o objeto

dirigir-se diretamente ao objeto

dirigir-se ao objeto, parar uma vez tocar o objeto

Figura 1 - Somatória dos sete dias de observação para cada uma das categorias avaliadas, para cada animal Jaboticabal - 2006

eqüinos ${ }^{17}$ associados à esterilidade do ambiente utilizado nas observações ${ }^{3,4}$ tenham influenciado na resposta apresentada pelos animais.

Grande parte das tendências emocionais e comportamentais é fixada muito cedo na vida dos eqüinos, quando situações novas assumem caráter lúdico, e o sucesso frente às experiências vividas influencia no desenvolvimento do temperamento do animal, pois é base da autoconfiança. Assim, se impostas no tempo certo, tais novidades 
Tabela 2 - Tempo total de toque nos objetos durante as sete sessões de observação - Jaboticabal - 2006

\begin{tabular}{lcc}
\hline & Tempo (minutos) & Tempo (\%) \\
\hline Égua $n^{\circ} 1$ & $1,5 *$ & $3,29 *$ \\
Égua $n^{\circ} 3$ & $0,5 *$ & $1,10 *$ \\
Égua $n^{\circ} 5$ & $4,0^{*}$ & $8,77 *$ \\
Égua $^{\circ}{ }^{\circ}$ & $2,8 *$ & $6,14 *$ \\
\hline Total éguas $^{*}$ & $8,8 *$ & $19,30 \#$ \\
\hline Potro $^{\circ} 2$ & 7,7 & 16,89 \\
Potro $n^{\circ} 4$ & 7,3 & 16,01 \\
Potro $n^{\circ} 6$ & 16,6 & 36,40 \\
Potro $n^{\circ} 8$ & $5,2 *$ & $11,40 *$ \\
\hline Total potros & 36,8 & 80,70 \\
\hline TOTAL & 45,6 & 100
\end{tabular}

* estatisticamente diferente do valor encontrado para o animal $\mathrm{n}^{\circ} 6$ (SNK, $\mathrm{p} \leq 0,05$ ); \# estatisticamente diferente do valor encontrado para os potros (teste-t, $\mathrm{p} \leq 0,05$ )
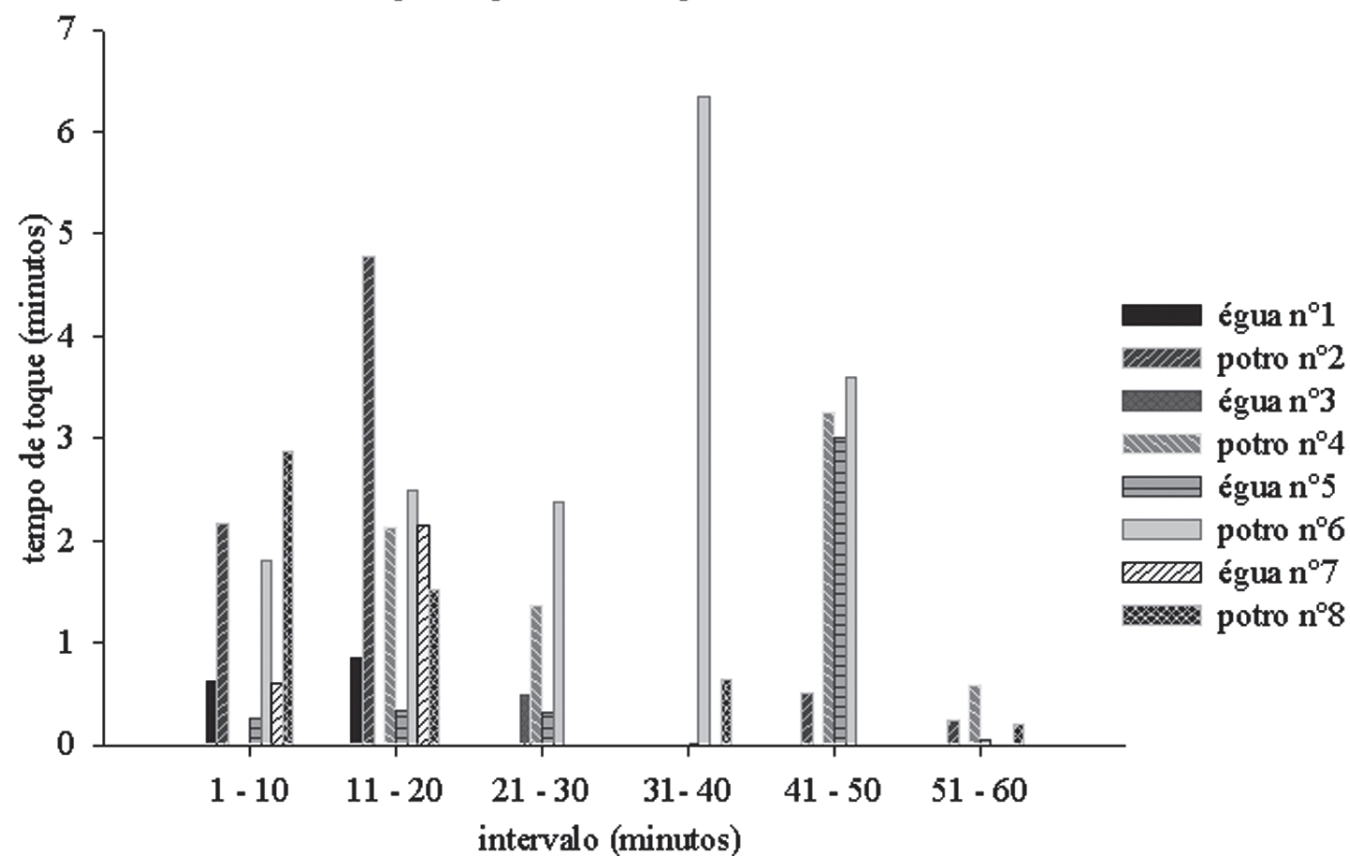

Figura 2 - Tempo de toque nos objetos, considerando intervalos de 10 minutos - Jaboticabal - 2006

encorajam o desenvolvimento das habilidades, desde que a diversão seja agradável e orientada ao propósito para o qual destina-se o animal na vida adulta. ${ }^{28}$ Além disso, o fato dos animais não serem intimidados pelos objetos promoveu feedback positivo para que eles continuassem a explorar as novidades impostas. ${ }^{18}$
Possivelmente, o sucesso frente às experiências vividas e as diferenças individuais tenham influenciado de modo direto o tempo gasto na manipulação dos objetos por cada animal.

Além das diferenças individuais, notou-se que os potros exibiram freqüências maiores de exploração e despenderam maior 
tempo na investigação do que lhes motivava, seguindo o padrão natural da espécie, visto que é no primeiro ano de vida que os eqüinos mais interagem com o meio ${ }^{17}$. A aproximação solitária dos potros após prévia aproximação das éguas provavelmente reflita que os jovens imitem suas mães ou que adquiram confiança com as atitudes delas. Ademais, quando muito jovens os potros não se distanciam de suas mães e são extremamente dependentes dessas e só após o primeiro mês de vida é que as atividades sociais entre potros tornamse mais freqüentes. ${ }^{29,30}$

O fato dos potros olharem diretamente para o que lhes atrai corrobora com o que foi descrito por Waring ${ }^{18}$, que descreve que eles viram a cabeça e direcionam as orelhas para o foco de atenção até classificarem como irrelevante ou merecedora de alguma ação como fuga ou interação e, neste caso, antes de alcançar o objeto, o animal o observa e só então inicia a aproximação, que é realizada em círculos a uma determinada distância que revela seu grau de apreensão. O medo que acompanha os eqüinos durante as explorações atua como preventivo contra perigos em potencial e garante-lhes cuidado nas aproximações a objetos desconhecidos. ${ }^{31} \mathrm{~A}$ manipulação incluiu tocar o focinho, cheirar, mordiscar e tocar com os membros torácicos, como já foi descrito em estudos anteriores..$^{29,30}$

\section{Conclusões}

A introdução de objetos desconhecidos no ambiente gera curiosidade suficiente para motivar potros e éguas a exibirem comportamento exploratório semelhantes, todavia os potros apresentam maior atividade de manipulação e têm mais iniciativa de aproximação, sugerindo que estes sejam mais curiosos que éguas, embora a companhia da mãe pareça encorajá-los. Não é sempre o mesmo animal quem se aproxima primeiro do objeto desconhecido no ambiente, mas a predisposição para tal posição indica diferenças individuais no grau de curiosidade dos eqüinos.

\section{Exploratory behavior of foals and mares front introduction of new objects in their environment}

\section{Abstract}

Exploratory behavior is done by animals to increase their interaction to the environment after be stimulated by curiosity, when animal feels that is in a secured place. The objective of this study was to evaluate exploratory behavior of foals front of introduction of new objects in their environment. Four foals and mares were observed in seven day sections of 60 minutes each one, always with a new object. No differences were verified about frequencies of looking, going to or touching into foals and mares. Total time of touching was 45,6 minutes, divided in 64 touches, mainly in first 20 minutes of each observation. However there is no statistical difference into solitary or impaired approaches and in impaired approaches there is no differences into foals or mares initiatives, foals done more solitary approaches than mares. Four animals touched the objects in first place, suggesting predisposition to this position based in individual differences. So, we concluded that new objects can stimulate similarly foals and mares to exhibit exploratory behavior, but foals show more manipulation activity, suggesting that are more curious than mares and predisposition to touch objects first depends of individual differences.
Key words: Exploratory behavior. Curiosity. Horses. Foals. 


\section{Referências}

1 JOHNSON, J. I. States of activation: sleep, arousal and exploration. In.: HAFEZ, E. S. E. The behaviour of domestic animals. New York: Baillière Tindal, 1975. p. 63-72.

2 LORENZ, K. Comportamento exploratório ou curiosidade. In.: LORENZ, K. Os fundamentos da etologia. São Paulo: UNESP, 1995. p. 415-428.

3 MACKAY, P. C.; WOOD-GUSH, D. G. M. The responsiveness of beef-calves to novel stimulation - an interaction between exploration and fear. Applied Animal Ethology, v. 6, n. 4, p. 383-384, 1980.

4 STOLBA, A.; WOOD-GUSH, D. G. M. The behaviour of pigs in a semi-natural environment. Animal Production, v. 48, p. 419-425, 1989.

5 WOOD-GUSH, D. G. M. Social behaviour. In: WOOD-GUSH, D. G. M. Elements of ethology - a textbook for agricultural and veterinary students. New York: Chapman and Hall, 1983. p. 15-55.

6 DRAI, D.; KAFKAFI, N.; BENJAMINI, Y.; ELMER, G.; GOLANI, I. Rats and mice share common ethologically relevant parameters of exploratory behavior. Behavioural Brain Research, v. 125, n. 1/2, p. 133-140, 2001.

7 GENARO, G.; SCHMIDEK, W. R. The influence of handling and isolation postweaning on open field, exploratory and maternal behavior of female rats. Physiology and Behavior, v. 75, n. 5, p. 681-688, 2002.

8 GRAY, J. A.; LALLJEE, B. Sex differences in emotional behaviour in the rat: correlation between open-field defecation and active avoidance. Animal Behaviour, v. 22, n. 4, p. 856-861, 1974.

9 JONES, N.; KING, S. M.; DUXON, M. S. Further evidence for the predictive validity of the unstable elevated exposed plus-maze, a behavioural model of extreme anxiety in rats: Differential effects of fluoxetine and chlordiazepoxide. Behavioural Pharmacology, v. 13, n. 7, p. 525-535, 2002.

10 SILVERMAN, A. P. An ethologist's approach to behavioural toxicology. Neurotoxicology and Teratology, v. 10, n. 2, p. 85-92, 1988.

11 JONES, B. Effects of early environmental enrichment upon open-field behavior and timidity in the domestic chick. Developmental Psychobiology, v. 15, n. 2, p. 105-111, 2004

12 JENSEN, M. B.; VESTERGAARD, K. S.; KROHN, C. C.; MUNKSGAARD, L. Effect of single versus group housing and space allowance on responses of calves during open-field tests. Applied Animal Behaviour Science, v. 54, n. 2, p. 109-121, 1997.

13 TAKEDA, K.; SHUSUKE, S.; SUGAWARA, K. Familiarity and group size affect emotional stress in Japanese Black heifers. Applied Animal Behaviour
Science, v. 82, p. 1-11, 2003.

14 KLONT, R. E.; HULSEGGE, B.; HOVING-BOLINK, A. H.; GERRITZEN, M. A.; KURT, E.; WINKELMANGOEDHART, H. A.; DE JONG, I. C.; KRANEN, R. W. Relationships between behavioral and meat quality characteristics of pigs raised under barren and enriched housing conditions. Journal of Animal Science, v. 79, n. 11, p. 2835-2843, 2001.

15 WOOD-GUSH, D. G. M.; BEILHARZ, R. G. The enrichment of a bare environment for animals in confined conditions. Applied Animal Ethology, v. 10, n. 3, p. 209-217, 1983.

16 SIWAK, C. T.; TAPP, P. D.; MILGRAM, M. W. Behavioural correlates of age-associated cognitive changes in dogs. Disponível em: <http:// www.ivis.org >. Acesso em: 09 fev. 2006.

17 MCDONNELL, S. M. Behaviour of horses. In: JENSSEN, P. The ethology of domestic animals - an introductory text. London: $\mathrm{CABI}$, 2002. p. 119-129.

18 WARING, G. H. Investigative Behaviour. In: WARING, G. H. Horse behavior. New York: Elsevier, 2002. p. 91-95.

19 ANTONIADIS, E. A.; MCDONALD, R. J. Amygdala, hippocampus and discriminative fear conditioning to context. Behavior Brain Research, v. 108, n. 1, p. 1-19, 2000.

20 BAILEY, D. J.; KIM, J. J.; SUN, W.; THOMPSON, R. F.; HELMSTETTER, F. J. Acquisition of fear conditioning in rats requires the synthesis of mRNA in the amygdala. Behavioral Neuroscience, v. 113, n. 2, p. 276-282, 1999.

21 BARNETT, R. M. Model with three charmed quarks. Physical Review Letters, v. 34, n. 1, p. 41-43, 1975.

22 BARNETT, S. A. Movement in the living space. In: BARNETT, S. A. The rat: a study in behavior. Chicago: Aldine Publishing Co, 1963. p. 15-33.

23 BERLYNE, D. E. Conflict, arousal, and curiosity. New York: McGraw-Hill, 1960. 350 p.

24 MILIARESSIS, E.; ROMPRE P. P. Self-stimulation and circling: differentiation of the neural substrate by behavioral measurement with the use of the double pulse technique. Physiology and Behavior, v. 25, n. 6, p. 939-943, 1980.

25 WEINGARTEN, H. P.; WHITE, N. M. Exploration evoked by electrical stimulation of the amygdala of rats. Physiological Psychology, v. 6, n. 2, p. 229-235, 1978.

26 WOOD-GUSH, D. G. M. Exploratory behaviour. In: WOOD-GUSH, D. G. M. Elements of ethology - a textbook for agricultural and veterinary students. New York: Chapman and Hall, 1983. p. 130-133.

27 SAMPAIO, I. B. M. Estudo de dispersão de freqüência. In: SAMPAIO, I. B. M. Estatística aplicada à experimentação animal. Belo Horizonte: Fundação de 
Ensino e Pesquisa em Medicina Veterinária e Zootecnia, 1998. p. 105-117.

28 MILLS, D.; NANKERVIS, K. Desenvolvimento do comportamento durante a vida. In: MILLS, D.; NANKERVIS, K. Comportamento eqüino - princípios e prática. São Paulo: Roca, 2005. p. 50-62.

29 FAGEN, R. M.; GEORGE, T. K. Play behavior and exercise in young ponies (Equus caballus L.). Behavioral Ecology and Sociobiology, v. 2, n. 3, p. 267-269, 1977.

30 WARING, G. H. Play. In: WARING, G. H. Horse behavior. New York: Elsevier, 2002. p. 83-90.

31 WARING, G. H.; WIERZBOWSKY, S.; HAFEZ, E. S. E. The behaviour of horses. In.: HAFEZ, E. S. E. The behaviour of domestic animals. New York: Baillière Tindal, 1975. p. 330-369. 